\title{
FRAILTY OF BOEY SCORE IN PPU MORTALITY AND MORBIDITY PREDICTION- A PROSPECTIVE STUDY
}

\author{
Devadhason Darwin Brittoํㅜ, Alankrith Ramesh Kashyap², Sadasivam Prakash ${ }^{3}$
}

${ }^{1}$ Assistant Professor, Department of General Surgery, SRM Medical College Hospital \& Research Centre, Chennai.

${ }^{2}$ Assistant Professor (Registrar), Department of General Surgery, Dr. R.N. Cooper Hospital, Mumbai.

${ }^{3}$ Assistant Professor, Department of General Surgery, SRM Medical College Hospital \& Research Centre, Chennai.

\section{ABSTRACT}

\section{BACKGROUND}

Peptic ulcer is quite common in our country due to intake of non-steroidal anti-inflammatory drugs, alcohol, spicy diet, smoking and a stressful lifestyle. Almost everybody harbours Helicobacter pylori within them and prone to peptic ulcer. Peptic ulcer can have disastrous complications with one of them being perforation, which is a surgical emergency. Its effects can range from severe abdominal pain to hypotension, sepsis and shock. Hence, timely intervention is absolutely mandatory. Various scoring systems have been developed to prognosticate the morbidity and mortality of perforated peptic ulcer with Boey score being the most commonly followed in various healthcare setup. We tried to determine the role of Boey score in our patients with perforated peptic ulcer and analyse its limitations.

\section{MATERIALS AND METHODS}

Study was done on 50 patients in a span on 1 year with complaints of acute abdominal pain, with air under the diaphragm. They were surgically deemed fit as per anaesthesiologist and Graham live omental patch closure of perforation was done. Boey score was calculated and results evaluated.

\section{RESULTS}

There was progressive increase in Odds ratio and associated mortality of $0 \%, 13.8 \%, 27.3 \%$, and $100 \%$ with Boey scoring of $0,1,2$ and 3 respectively, similar to original Boey score. There was progressive increase in Odds ratio calculated for individual morbidity developed in our patients. Sample size of 50 patients, showed less significance on calculated p-value $(>0.05)$ in association with mortality and morbidity.

\section{CONCLUSION}

Boey score has limited role in prediction of mortality and morbidity in perforated peptic ulcer.

\section{KEYWORDS}

Boey Score, Perforated Peptic Ulcer.

HOW TO CITE THIS ARTICLE: Britto DD, Kashyap AR, Prakash S. Frailty of Boey score in PPU mortality and morbidity predictionA prospective study. J. Evolution Med. Dent. Sci. 2017;6(77):5482-5485, DOI: 10.14260/Jemds/2017/1190

\section{BACKGROUND}

Perforation has the maximum mortality rate than any other complication of peptic ulcer at $15 \%$, with a fact that it is a surgical emergency. Patients typically present with sudden, severe progressive epigastric pain, with vomiting and fever supplemented by abdominal guarding/rigidity indicative of diffuse peritonitis. ${ }^{[1]}$ There is free air under the diaphragm on an erect chest radiograph.[1] Perforation of peptic ulcer is most common in first part of duodenum more on the anterior wall, and it is treated by healthy Graham's live omental patch surgery.[1] Surgery can be carried out by open or laparoscopic techniques, but less pain and reduced use of narcotic analgesia exists with the latter.[1] Whatever be the choice of technique, drains have to be kept post-surgery to suspect leak and all patients must undergo Anti-Helicobacter pylori treatment.[1]

Financial or Other, Competing Interest: None.

Submission 20-08-2017, Peer Review 13-09-2017,

Acceptance 19-09-2017, Published 25-09-2017.

Corresponding Author:

Alankrith Ramesh Kashyap,

R2/10, Riddhi Enclave,

Viman Nagar,

Pune-411014.

E-mail: koolchant@gmail.com

DOI: $10.14260 /$ jemds $/ 2017 / 1190$

\section{(c) (i) $\odot$}

Not only do advanced age, presence of diabetes, cirrhosis of liver are associated with high mortality but when they occur in concurrence with perforated gastric ulcer, pose a catastrophe as compared to perforated duodenal ulcer.[2] Risk stratification for post-operative mortality/morbidity due to perforated peptic ulcer was predicted by score devised by Boey et al in late $80 \mathrm{~s}^{[2]}$ and there is evidence that more conversion rates from laparoscopic to open surgery occur with higher Boey scores.[2,3]

\section{Aims and Objectives \\ Aim \\ To predict mortality and morbidity in patients with perforated peptic ulcer using Boey score.}

\section{Objectives}

1. Correlation of mortality and morbidity with Boey score.

2. Analyse limitations of Boey score.

Morbidity expressed in terms of wound infection, wound dehiscence, suture leak, abscess formation, respiratory infection, UTI (Urinary Tract Infections).

\section{MATERIALS AND METHODS}

A prospective observational study on 50 patients was conducted for a period of 1 year. 


\section{Inclusion Criteria}

All patients with perforated peptic ulcer managed surgically.

\section{Exclusion Criteria}

Patients with perforated peptic ulcer disease managed conservatively.

\section{METHODOLOGY}

All patients who were planned for the study came to casualty with upper abdominal pain, vomiting, fever. X-ray erect abdomen showed gas under diaphragm suggestive of hollow viscous perforation, with perforated peptic ulcer being the case. All these patients were planned for emergency surgery but those patients who were not fit to undergo surgery (due to severe comorbidities and anaesthesiologist-judged risk benefit ratio), were managed conservatively with peritoneal drain and hence excluded from the study. Finally, a total sample of fifty patients were included for the study. All patients with a diagnosis of perforated peptic ulcer were included in this study after their informed consent. Boey score was calculated for every enrolled patient prior to surgery.

\section{RESULTS}

Boey score includes:

I. Presence of pre-operative shock (systolic BP $<90$ $\mathrm{mmHg}$,

II. Time of perforation prior to surgery $>24$ hours.

III. Concomitant severe medical illness.
A score ranging from 0 to 3 was assigned depending on the above criteria (Table 1).

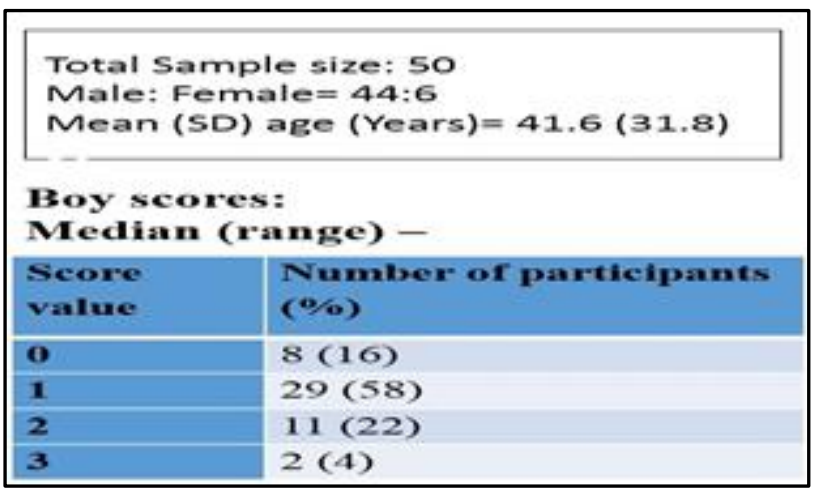

Table 1. Boey Score in Our Study Population

These patients were managed surgically by upper midline laparotomy and live omental patch closure of the perforation. All these patients received pre and post-operative antibiotics. Postoperatively observed mortality and morbidity of the patients were correlated with Boey score. Data analysis and conclusions were drawn using statistical methods. AntiHelicobacter pylori regimen was a part of treatment protocol for all patients.

Dependent variables (mortality and morbidity) are categorical and so only Odds ratio could be used which is indicative of the strength of association with the independent variable (Boey score). Chi-square test was done which revealed p-value $>0.05$ (not significant). Software used- SPSS version 16, Microsoft Excel 2007.

\begin{tabular}{|l|l|l|}
\multicolumn{3}{|c|}{ Boey score association with with mortality } \\
Score value $(\mathbf{n})$ & $\begin{array}{l}\text { Number of } \\
\text { deaths }(\%)\end{array}$ & $\begin{array}{l}\text { Odds ratio } \\
{[95 \% \text { confidence interval] }}\end{array}$ \\
\hline $\mathbf{0}(\mathbf{n}=8)$ & 0 & NA \\
\hline $\mathbf{1}(\mathbf{n}=29)$ & $4(13.8)$ & $1.2[0.1,12.7]$ \\
\hline $\mathbf{2}(\mathbf{n}=11)$ & $3(27.3)$ & $4.6[0.4,51.1]$ \\
\hline $\mathbf{3}(\mathbf{n}=2)$ & $2(100)$ & $16[0.7,383]$ \\
\hline
\end{tabular}

$\mathrm{P}>0.05$ (not significant)

\section{Boey score association with any post-operative complication (morbidity)}

\begin{tabular}{|l|l|l|}
\hline Score value (n) & $\begin{array}{l}\text { Number of } \\
\text { diseased }(\%)\end{array}$ & $\begin{array}{l}\text { Odds ratio } \\
{[95 \% \text { confidence interval] }}\end{array}$ \\
\hline $0(n=8)$ & $3(37.5)$ & NA \\
\hline $1(n=29)$ & $12(41.4)$ & $1.2[0.2,5.9]$ \\
\hline $2(n=11)$ & $5(45.5)$ & $1.4[0.2,8.9]$ \\
\hline $3(n=2)$ & 0 & NA \\
\hline
\end{tabular}

$P>0.05$ (not significant)

Table 2. Boey Score Association with Mortality and Morbidity

\begin{tabular}{|l|l|l|}
\hline Boey Score value (n) & $\begin{array}{l}\text { Number of patients with } \\
\text { wound infection (\%) }\end{array}$ & $\begin{array}{l}\text { Odds ratio [95\% confidence } \\
\text { interval] }\end{array}$ \\
\hline $\mathbf{0}(\mathbf{n}=\mathbf{8})$ & $3(37.5)$ & NA \\
\hline $\mathbf{1}(\mathbf{n}=\mathbf{2 9})$ & $9(31)$ & $0.75[0.16,3.8]$ \\
\hline $\mathbf{2}(\mathbf{n}=\mathbf{1 1})$ & $5(45.5)$ & $1.4[0.2,8.9]$ \\
\hline $\mathbf{3 ( n = 2 )}$ & 0 & NA \\
\hline Boey Score value (n) & $\begin{array}{l}\text { Number of patients with } \\
\text { wound dehiscence (\%) }\end{array}$ & $\begin{array}{l}\text { Odds ratio [95\% confidence } \\
\text { interval] }\end{array}$ \\
\hline $\mathbf{0}(\mathbf{n}=\mathbf{8})$ & 0 & NA \\
\hline $\mathbf{1}(\mathbf{n}=\mathbf{2 9})$ & $2(6.9)$ & $0.6[0,7.4]$ \\
\hline $\mathbf{2}(\mathbf{n}=\mathbf{1 1})$ & 0 & NA \\
\hline $\mathbf{3 ( n = 2 )}$ & 0 & NA \\
\hline
\end{tabular}

Table 3. Boey Score Association with Wound Infection and Wound Dehiscence (p-value > 0.05, Not Significant)

\begin{tabular}{|l|l|l|}
\hline Boey Score value (n) & $\begin{array}{l}\text { Number of patients with } \\
\text { suture leak (\%) }\end{array}$ & $\begin{array}{l}\text { Odds ratio [95\% confidence } \\
\text { interval] }\end{array}$ \\
\hline $\mathbf{0 ( n = 8 )}$ & 0 & NA \\
\hline $\mathbf{1}(\mathbf{n}=\mathbf{2 9})$ & $1(3.4)$ & $0.3[0,5]$ \\
\hline $\mathbf{2}(\mathbf{n}=\mathbf{1 1})$ & 0 & NA \\
\hline $\mathbf{3 ( n = 2 )}$ & 0 & NA \\
\hline Boey Score value (n) & $\begin{array}{l}\text { Number of patients with } \\
\text { abscess formation (\%) }\end{array}$ & $\begin{array}{l}\text { Odds ratio [95\% confidence } \\
\text { interval] }\end{array}$ \\
\hline $\mathbf{0 ( n = 8 )}$ & 0 & NA \\
\hline $\mathbf{1}(\mathbf{n}=\mathbf{2 9})$ & $1(3.4)$ & $0.1[0.1 .4]$ \\
\hline $\mathbf{2 ( n = 1 1 )}$ & $2(18.2)$ & $0.7[0.1,6.1]$ \\
\hline $\mathbf{3 ( n = 2 )}$ & 0 & NA \\
\hline
\end{tabular}

Table 4. Boey Score Association with Suture Leak and Abscess Formation (p-value $>0.05$, Not Significant) 


\begin{tabular}{|c|c|c|}
\hline Boey Score value (n) & $\begin{array}{l}\text { Number of patients with } \\
\text { Respiratory infection (\%) }\end{array}$ & $\begin{array}{l}\text { Odds ratio }[95 \% \\
\text { confidence interval] }\end{array}$ \\
\hline $0(n=8)$ & $2(20)$ & NA \\
\hline $1(n=29)$ & $5(17.2)$ & $0.6[0.1,4]$ \\
\hline $2(n=11)$ & $3(27.3)$ & $1.1[0.1,9]$ \\
\hline $3(n=2)$ & 0 & NA \\
\hline Boey Score value (n) & \begin{tabular}{|l|} 
Number of patients with \\
Urinary Tract Infection (\%)
\end{tabular} & $\begin{array}{l}\text { Odds ratio }[95 \% \\
\text { confidence interval] }\end{array}$ \\
\hline $0(n=8)$ & 0 & NA \\
\hline $1(n=29)$ & $2(6.9)$ & $0.6[0,7.4]$ \\
\hline $2(n=11)$ & $1(9)$ & $0.8[0.14 .9]$ \\
\hline $3(n=2)$ & 0 & NA \\
\hline
\end{tabular}

Table 5. Boey Score Association with Respiratory Infection and UTI (p-value > 0.05, Not Significant)

\section{DISCUSSION}

The scenario of Perforated Peptic Ulcer (PPU) is still common accounting to a mortality rate of $70 \%$ with duodenal ulcers being the most frequently encountered 10 cases/ 1 lakh population. ${ }^{[4]}$ Most often, perforation develops on anterior wall of duodenum followed by antrum and unusually at lesser curvature. ${ }^{[4]}$ Boey et al developed a score to predict morbidity and mortality associated with PPU via use of three parameters with score ' 1 ' each, total scoring: 0-3; viz. (a) Preoperative shock (BP $<90 \mathrm{mmHg}$ ), (b) duration of perforation more than 24 hours, (c) concomitant medical illness. ${ }^{[4]}$ His study revealed that the Odds ratio of developing mortality/morbidity steadily increased with increase in Boey score, as such mortality rates of $0 \%, 10 \%, 45.5 \%$ and $100 \%$ coincided with Boey scores of 0, 1, 2 and 3 respectively. ${ }^{[4]}$ In our study, we had progressive increase in Odds ratio \& associated mortality of $0 \%, 13.8 \%, 27.3 \%$, and $100 \%$ with Boey scoring of $0,1,2$ and 3 respectively, similar to original Boey score (Table 2).

Original Boey score defined major medical illness as nonspecific cardiorespiratory disease, diabetes, pre-hepatic coma but did not include active malignant disease, Acquired Immune Deficiency Syndrome (AIDS), myocardial infarction, liver cirrhosis. ${ }^{[5]}$

Mean age in Original Boey study was 51 years and omitted advanced age, elderly women population with ulcerogenic medications like Non-steroidal Antiinflammatory Drugs (NSAIDS), sample size from developing countries, prognostic factors like tachycardia (Heart Rate $>100$ beats/minute), acute renal failure, delay from time of perforation to hospital admission; thus causing extremely variable results in successive studies in literature.[5,6,7]

Variability in admission time since onset of symptoms of PPU especially in young alcoholics and consumptions of Aspirin in elderly independently adds to post-operative complication rate of $17-60 \%$ independent of Boey score calculated for a given patient.[7,8] Mortality reported in our study for Boey score 2 alone was $27.3 \%$ similar to literature reports that range from $30-60 \% .{ }^{[8]}$

Independent studies conducted by Ahmad et al, Nichakankitti et al and Nwashilli exposed Boey score, though easy to calculate and increasing Boey score was associated with high mortality, yet it had poorest ability to predict mortality/morbidity and was non-significant ( $p>0.05)$, so prompt diagnosis and succedent stratification of high risk patients may prove beneficial. $[4,6,9,10]$ Our sample size was 50 patients which showed less significance on calculated $p$-value $(>0.05)$ in association with mortality, however, a trend was observed; meaning there is likely to observe a significance if you increase sample size i.e. if the same findings were replicated on a larger population (Tables 2). Boey score association with individual comorbidities were also found to be non-significant ( $\mathrm{p}>0.05$ ) (Tables $3,4,5$ ).

As Boey score did not take into account age, sex, renal dysfunction, peritonitis, studies to compare other predictive models like American Society of Anesthesiology (ASA), Mannheim Peritonitis Index (MPI), Peptic Ulcer Perforation (PULP) scoring systems to Boey score were done- all of which exhibited moderate accuracy in prediction of mortality which was attributed to geographical, demographical and social diversity. ${ }^{[6,11,12,5]}$

Buck and colleagues on the other hand expressed the meagre ability of Boey score in predicting mortality and morbidity status.[13] Their multicentre study also stated that the ASA score, and sepsis score were not able to provide convincing results in prognostication of patients.[13]

Presence of comorbidities which are divergent per patient combined with increasing patient age not only makes diagnostic decisions operose but also further delays operation time thus adding on to mortality than death due to PPU in itself.[14]

Metabolic acidosis, malnutrition, hypoalbuminaemia, smoking, female gender are essential isolated risk factors in development of mortality due to PPU.[7,12]

Besides, symptoms and their duration prior to definitive surgery are equally essential to prognosticate patient condition as it may progress to peritonitis and Multi-Organ Dysfunction Syndrome (MODS).[15] Additionally, individual biological response and other unforeseen events can also influence overall post-operative outcome of the patient hence making accurate pre-operative prediction cumbersome.[15] This was observed in our study by the diverse post-operative complications developed in our small number of patients.

Lee et al did a ten year retrospective study and realised that ulcer size was directly proportional to the mortality.[16] Boey score does not take into account ulcer size and it cannot anticipate specific post-operative complications.[16] Also they compared Boey score and Acute Physiology and Chronic Health Evaluation II (APACHE-II) scores and found poor competency to foresee morbidity by Boey score, though both demonstrated moderate veracity in mortality prediction. [16] We record similar situations in our study that death occurred in Boey scores 2 and 3, but the severity of comorbidity that prevailed prior could not be clearly defined, hence prediction of specific morbidity by Boey score could not be confirmed.

Finally, as scoring systems are applicable only for specific populations, at limited times, in unique geographical and demographic situations, with distinct patient characteristics and attributes, for definite comorbidities like hypoalbuminaemia, anaemia, leucocytosis; a validating system for each hospital should be enforced pertaining to its own population to ease prediction of mortality and morbidity.[17,18,19] Despite provision of such a model in the future, a sound judgement by the surgeon outweighs and surpasses all predictive models.[17] $\mathrm{He}$ can assess risk to benefit ratio, evaluate the available facilities, gauge ethical contentions, and apprise necessary changes thus making an astute clinical decision for treatment custom-made for every patient with PPU; which finally will improve the overall outcome.[17] 


\section{Limitations of Boey Score Exhibited in this Study}

1. Most patients were referred from peripheral hospitals and delay in surgery from onset of symptoms was variable for every patient, hence accurate history from onset of symptoms to admission time and subsequent surgery could not be ascertained due to recall bias.

2. Patients with comorbidities were added to the parameter as per Original Boey score, yet each comorbidity could serve as an independent factor to cause post-operative morbidity/mortality causing variable results.

3. Old aged patients had more than one comorbidity and their combined effects could misconstrue the Boey score.

4. Most of the patients in our study were malnourished due to poor socioeconomic status and had smoking/alcohol habits, thus high risk for any surgical intervention.

5. Many patients went through a prequel of morbidity postoperatively before they succumbed. Thus, the morbidity and mortality in a given patient could not be clearly delineated.

6. Many middle aged and elderly patients had a history of aspirin intake due to past impaired cardiac events and many females consumed NSAIDs due to history of joint pains, hence surgery was done under high intra and postoperative complication risk. Medication history does not form a part of Boey score calculation.

7. Ulcer size was not taken into account during the study as it was not a part of Boey score.

8. Sample size was small.

\section{CONCLUSION}

It is seen from this study that many parameters can alter the course of the disease irrespective of the Boey score, thus showing its imperfection. A high Boey score can only reveal mortality but the mortality and morbidity may not occur due to PPU per se. Other parameters like age, multiple comorbidities, medication, vital signs, infections, malignancies, ulcer size must also be 'borne in mind' for adequate prediction of mortality/morbidity. Nevertheless, Boey score that was formulated two decades ago has 'laid the first stone' in genesis of newer scoring systems and better clinical judgements in treatment of Perforated Peptic Ulcer.

\section{REFERENCES}

[1] Townsend CM, Beauchamp RD, Evers BM, et al. Sabiston textbook of surgery. 19th edn. Elsevier Saunders 2012:1196.

[2] Fischer JE, Daniel BJ, Frank B, et al. Fischer's mastery of surgery. $6^{\text {th }}$ edn. Lippincott Williams \& Wilkins 2012:1030-41.

[3] Vincenzo M. The role of laparoscopy in emergency abdominal surgery. Springer-Verlag Italia 2012:17.

[4] Agarwal A, Jain S, Meena LN, et al. Validation of Boey's score in predicting morbidity and mortality in peptic perforation peritonitis in Northwestern India. Tropical Gastroenterology 2016;36(4):256-60.

[5] Møller MH, Engebjerg MC, Adamsen S, et al. The Peptic Ulcer Perforation (PULP) score: a predictor of mortality following peptic ulcer perforation. A cohort study. Acta Anaesthesiol Scand 2012;56(5):655-62.
[6] Ahmad M, Nawaz H, Khan M, et al. Frequency of high Boey score and its one month mortality after surgery for perforated peptic ulcer disease. KJMS 2013;6(2):253-7.

[7] Menekse E, Kocer B, Topcu R, et al. A practical scoring system to predict mortality in patients with perforated peptic ulcer. World J Emerg Surg 2015;10(1):7.

[8] Lohsiriwat V, Prapasrivorakul S, Lohsiriwat D. Perforated peptic ulcer: clinical presentation, surgical outcomes and the accuracy of the Boey scoring system in predicting postoperative morbidity and mortality. World J Surg 2009;33(1):80-5.

[9] Nichakankitti N, Athigakunagorn J. The accuracy of prognostic scoring systems for post-operative morbidity and mortality in patients with perforated peptic ulcer. International Surgery Journal 2016;3(1):286-90.

[10] Nwashilli NJ, Nwajei CO. Boey score in predicting mortality in patients with perforated peptic ulcer. Annals of Biomedical Sciences 2014;13(2):165-71.

[11] Anbalakan K, Chua D, Pandya GJ, et al. Five year experience in management of perforated peptic ulcer and validation of common mortality risk prediction models - are existing models sufficient? A retrospective cohort study. International J Surgery 2015;14:38-44.

[12] Chung KT, Shelat VG. Perforated peptic ulcer - an update. World Journal of Gastrointestinal Surgery 2017;9(1):1-12.

[13] Buck DL, Vester-Andersen M, Møller MH. Accuracy of clinical prediction rules in peptic ulcer perforation: an observational study. Scand J Gastroenterol 2012;47(1):28-35.

[14] Bertleff MJ, Lange JF. Perforated peptic ulcer disease: a review of history and treatment. Digestive Surgery 2010;27(3):161-9.

[15] Nachiappan M, Litake MM. Scoring systems for outcome prediction of patients with perforation peritonitis. J Clinical and Diagnostic Research 2016;10(3):PC01-05.

[16] Lee FYJ, Leung KL, Lai BSP, et al. Predicting mortality and morbidity of patients operated on for perforated peptic ulcers. Archives of Surgery 2001;136(1):90-3.

[17] Rix TE, Bates T. Pre-operative risk scores for the prediction of outcome in elderly people who require emergency surgery. World Journal of Emergency Surgery 2007;2(1):16.

[18] Thorsen K, Søreide JA, Søreide K. What is the best predictor of mortality in perforated peptic ulcer disease? A population-based, multivariable regression analysis including three clinical scoring systems. Journal of Gastrointestinal Surgery 2014;18(7): 1261-8.

[19] Thorsen K, Søreide JA, Søreide K. Scoring systems for outcome prediction in patients with perforated peptic ulcer. Scandinavian Journal of Trauma Resuscitation and Emergency Medicine 2013;21(1):25. 